\title{
5th International ACC Symposium: Introduction
}

\author{
Gary D. Hammer ${ }^{1}$
}

Received: 27 November 2015 / Accepted: 7 December 2015 / Published online: 4 January 2016

(C) Springer Science+Business Media New York 2015

Dear colleagues and HOCA readership,

This Special Edition of Hormones \& Cancer celebrates the 100th Anniversary of the Endocrine Society. This edition is dedicated primarily to the Society's support of adrenal neoplasia research. We highlight advances in this area of investigation with a series of review summaries from the various sessions of the recent 5th International Adrenocortical Carcinoma Symposium held at the University of Michigan in October 2015.

Adrenocortical cancer (ACC) is a rare disease; therefore, general information and medical education are often not as easily available as for other common diseases. Even within the medical societies, there is rarely a platform for basic science and clinical studies focusing on ACC.

The University of Michigan has been involved in adrenal research for many decades. In the 1950s, Jerome Conn described primary aldosteronism, in the $1980 \mathrm{~s}$, metaiodobenzylguanidine (MIBG) and 6-betaiodomethyl-19-norcholesterol (NP59) were developed at the University of Michigan for the use of adrenomedullary and adrenocortical imaging, respectively, and since the 1990s, the Endocrine Oncology Program under the guidance of Ed Schteingart developed into an international

Associate Editor-Hormones and Cancer

Program Committee - 5th International Adrenal Cancer Symposium

Gary D. Hammer

ghammer@med.umich.edu

Miller Schembechler Professor of Adrenal Cancer, Director of Endocrine Oncology (Comprehensive Cancer Center), 1528 BSRB, 109 Zina Pitcher Place, University of Michigan, Ann Arbor, MI 48109, USA referral center for patients with the diagnosis of adrenal cancer. Ed Schteingart organized the first International Adrenal Cancer Conference in Ann Arbor in 2003, which was followed by a conference in Ann Arbor in 2008, in Wuerzburg in 2011, and Paris in 2013. This last October, researchers and physicians were welcomed back to Ann Arbor for the 5th International Adrenal Cancer Symposium hosted by the Endocrine Oncology Program of the Comprehensive Cancer Center and the associated Adrenal Program of the University of Michigan.

The last couple of years have been marked by international collaborations and large-scale efforts to gain a detailed understanding of the molecular makeup of adrenal cancer, which we now hope to translate into the care of our patients. With the help of friends and colleagues within the adrenal cancer community, the Program Committee compiled an exciting program that aimed to reflect the current efforts in clinical and basic research of ACC. We are particularly grateful to the many patients and families who accepted our invitation to a dedicated patient session on ACC and who have traveled here to participate in this Symposium.

The productive Symposium served to educate, enhance discovery, and facilitate the development of effective treatments for this disease. It is through the generosity of people - both public and private donations - that we are able to continue this biennial event.

The conference was organized into a number of sessions aligned to a specific theme, research area, or clinical issue. Written by session chairs and/or experts in the field, the reviews in the Special Edition are designed to serve as summaries and/ or reviews of the topics covered in the individual sessions.

Symposium information, links, photographs, and video interviews with leaders of the Endocrine Society and those associated with the Symposium can be found in http:/www. mcancer.org/adrenal-cancer/adrenal-symposium 
Videos also can be viewed in https://www.youtube.com/ playlist? list $=$ P L N xq P - X b H 8 B JVxw Jn6y J Q O fVzA8wLZVB
Congratulations to the Endocrine Society and to all adrenal researchers and clinicians for the last 100 years of progress as we look forward to the next 100 years of discovery. 